University of Nebraska - Lincoln

DigitalCommons@University of Nebraska - Lincoln

\title{
8-2005
}

\section{Evolutionary Algorithm for the Placement of Fluid Power Valves on a Valve Stand}

Trichy M. Kethara Pasupathy

Ravi Teja Seethamraju

Robert G. Wilhelm

Follow this and additional works at: https://digitalcommons.unl.edu/mechengfacpub

Part of the Mechanics of Materials Commons, Nanoscience and Nanotechnology Commons, Other Engineering Science and Materials Commons, and the Other Mechanical Engineering Commons

This Article is brought to you for free and open access by the Mechanical \& Materials Engineering, Department of at DigitalCommons@University of Nebraska - Lincoln. It has been accepted for inclusion in Mechanical \& Materials Engineering Faculty Publications by an authorized administrator of DigitalCommons@University of Nebraska Lincoln. 

Copyright (C) 2005 Springer-Verlag London Limited. Used by permission.

Submitted March 15, 2004; accepted October 14, 2004; published online May 25, 2005.

\title{
Evolutionary Algorithm for the Placement of Fluid Power Valves on a Valve Stand
}

\author{
Trichy M. Kethara Pasupathy, ${ }^{1}$ Ravi Teja Seethamraju, ${ }^{2}$ and \\ Robert G. Wilhelm ${ }^{3}$
}

1. Health Science Center-Jacksonville, University of Florida, Jacksonville, Florida, USA

2. Siemens Medical Solutions MGH-NMR Center, Charlestown, Massachusetts, USA

3. Department of Mechanical Engineering, University of North Carolina at Charlotte, Charlotte, North Carolina, USA

Corresponding author - T. M. K. Pasupathy, Health Science Center-Jacksonville, University of Florida, 655 W. 8th St., Jacksonville, FL 32209, USA, email trichy.pasupathy@jax.ufl.edu

\begin{abstract}
The choice of placement of fluid power valves on a valve stand and routing by pipes has an impact on operational costs. Choosing the right placement that provides optimum routing configuration or determining the optimum routing for a chosen placement are both computationally hard problems. An evolutionary algorithm (EA), to minimize operational costs while optimizing placement and routing of valves, is developed here. The best practices in the industry are abstracted and implemented in the EA. In this paper, the algorithm and its performance for examples with varying complexities are presented. Our results meet or exceed experienced designers' solutions.
\end{abstract}

\section{Introduction}

Fluidpower systems enable transmission of energy via fluid flow. Often for systems with flows beyond 160 liters per minute (LPM), the functional logic is provided with independent valves, and metal pipes interconnect all the components of the system. Such high-flow systems are installed in steel mills, machine tools, endurance test-benches and several other applications. Other methods exist that use solid metal blocks with drilled holes that substitute the piping. In this paper, we discuss systems that use metal pipes for plumbing. 
The design configuration is developed with a circuit diagram - a symbolic representation of the actual system. Consider Figure 1 that shows an example of a fluidpower circuit diagram with four different valves. Fluid from the pump is directed into the actuators by the valves that also control both pressure and flow. The physical construction of a generic valve in the circuit is shown in Figure 2. The valves come in different sizes and shapes based on their function. Each valve has ports, for fluid flow, that are designated with capital letters and are also shown in the circuit diagram. The circuit also shows solid interconnecting lines between the ports of the valves. These interconnections are achieved using metal pipes for circuits.

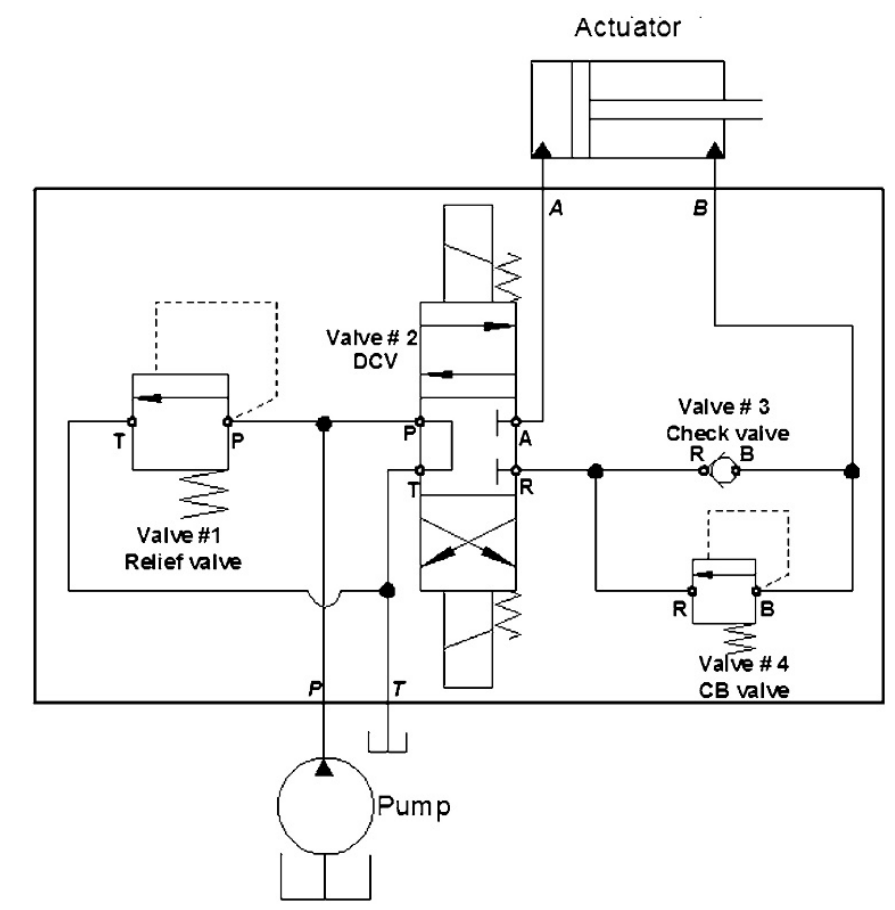

Figure 1. An example hydraulic circuit
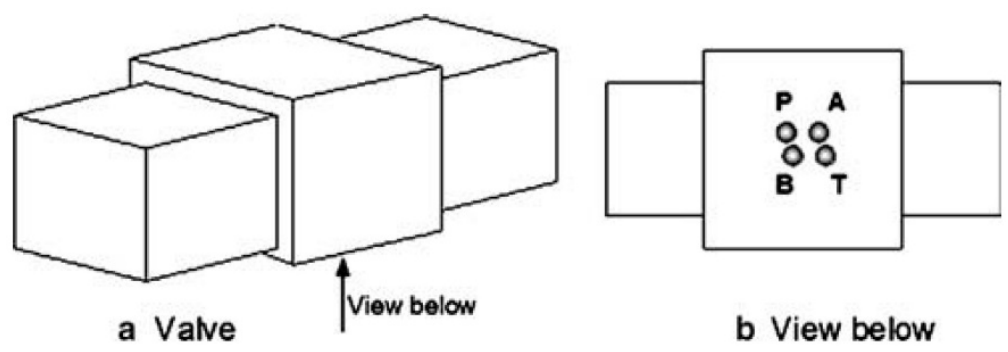

b View below

Figure 2. Physical construction of a hydraulic valve 
The physical realization of the circuit of Figure 1 is shown in Figure 3a. The valve-stand, a metal plate, is divided into four equal-sized cells and on each cell (on the valve side) a valve is mounted. The openings to the ports of the valves are made available on the other side, plumbing side, through cutouts on the metal plate. This side (Fig. $3 b$ ) is used for plumbing the ports. The optimal routing for the placement in Figure 3a is shown in Figure 3b. Alternatively, consider the placement and routing shown in Figure 3c, d, respectively. The routing (Fig. 3d) from the placement shown in Figure 3c saves approximately 15\% in plumbing length, compared to the routing in Figure 3b. An increase in plumbing length leads to increase in pressure drop, thereby increasing operational costs. However, selecting the right placement is not trivial. If we consider the valve-stand to be a 2-D matrix and $n$ is the number of valves in the circuit, the number of possible combinations for the placement is given below as

$$
\frac{\left(n^{2}\right) !}{\left(n^{2}-n\right) !}
$$

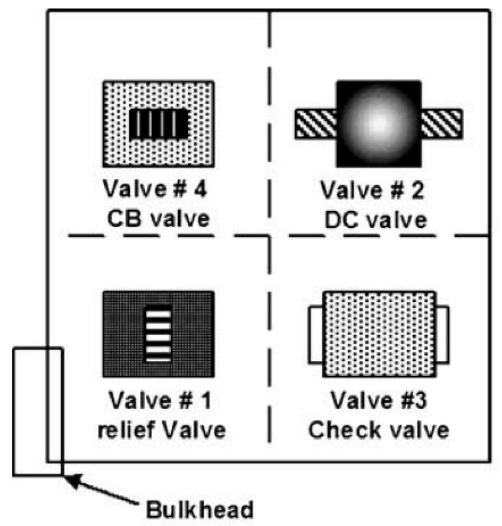

a. Valve side

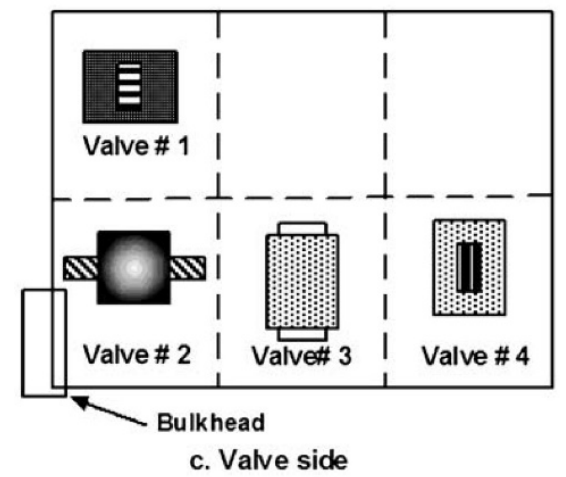

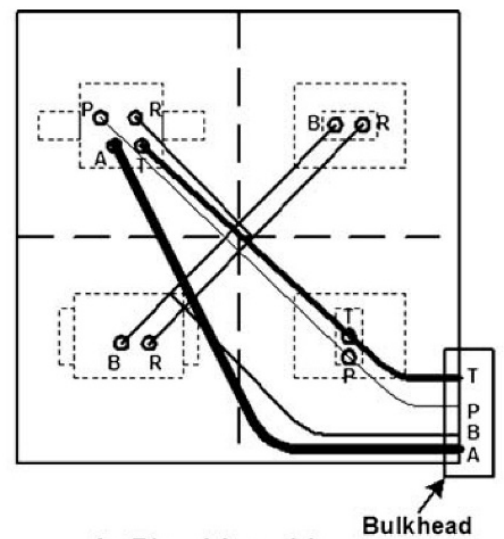

b. Plumbing side

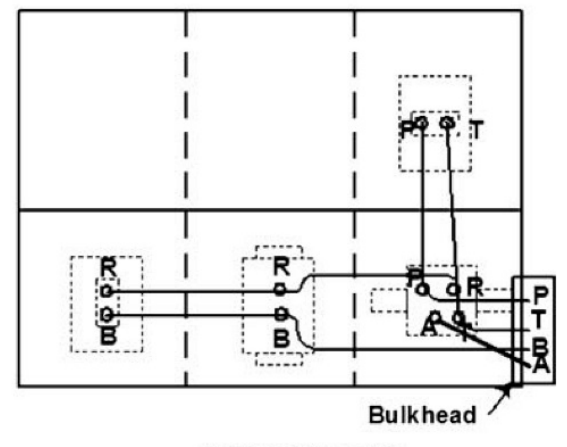

d. Plumbing side

Figure 3. (a) A possible arrangement of valves of the example circuit, and (b) is drawn as though the valve-stand is turned over, just as a page is turned over in a book to look into the next page; (c) and (d) alternative placement and routing 
These types of placement problems, in general, are referred to as the quadratic assignment problem or QAP [1] and proven to be computationally hard. Algorithms based on Darwin's evolutionary theory have been successfully applied to solve such problems.

In this paper, we transfer the best practices approach from the industry to an instance of an evolutionary algorithm (EA) to determine the placement for optimal routing. A review of related work is presented in the next section. Following the review, we describe the notations and establish the problem and set up the objectives for the solution. Subsequently, following a short note on the generic EA, the algorithm is developed. After the algorithm, the results and performance from testing the algorithm with circuits of different complexity are presented. Finally, conclusions are presented.

\section{Review of related work}

Fluidpower design guidebooks by authors like Henke [2], list the equations, factors, and components that introduce pressure drop in circuits. They recommend that to analyze a circuit completely all factors that contribute to the pressure drop-such as the length of the plumbing (major losses), connectors and bends (minor losses), and entry and exit ports of components - must be taken into account. Existing standards like [3] provide tips on the use of connectors. Software $[4,5]$ is available that help the designer to visualize the plumbing and plan the necessary components for the installation. Apart from tips and experiencebased practices pertinent to specific industries, extensive literature is not available for this problem. However, similar problems are researched extensively for (a) electronic circuits [6] and (b) high volume-selling cartridge valve designs (<160 LPM) currently prevalent in fluidpower industry. For electronics circuits that have millions of networks, a quicker, suboptimal but feasible solution is determined with the popular maze routing algorithms rather than an optimized solution that requires enormous resources [7]. In the fluidpower industry, computer programs that determine the interference of plumbing in the designs are popular [8].

The constraints of the valve stand placement problem are different. Here, we seek a global or near global optimal (satisfying [9]) solution via EA. In this paper, complete implementation details and exhaustive results are presented.

\section{Symbols and notation}

Consider the example circuit shown in Figure 1 that requires four valves to be interconnected. Valve \#2 has four ports represented by the letters $P, T, A$, and $R$, and valve \#1 has two ports $\mathrm{P}$ and $\mathrm{T}$. All ports in a circuit diagram designated with the same letter constitute a network. Each network has to be interconnected without physically interfering with other networks. For example the port $\mathrm{R}$ is present in valves \#2, 3, and 4 . Hence $\mathrm{R}$ forms a network. Similarly all networks in a circuit are to be identified to solve the problem. For this circuit, there are five networks namely $\mathrm{P}, \mathrm{T}, \mathrm{R}, \mathrm{A}$, and B. Also note that each valve will have one and only one port that participates in the same network, and each network in the circuit should have one or more ports that need to be interconnected. The single port net- 
works are used either as inputs or outputs from the valve stand to other fluidpower components such as actuators or pumps. The plumbing from single port networks terminates at a location called the bulkhead (refer Fig. 3).

The following symbols are used to derive the objective functions.

1. $V$, the set of valves in a circuit $=\left\{v_{1}, v_{2} \ldots v_{n}\right\}$ and $v_{q_{1}}(1 \leq q \leq n)$, represents any valve in the set

2. $\quad P$, the set of networks in the circuit $=\left\{p_{1}, p_{2} \ldots p_{s}\right\}$ and $(s \geq 1)$

3. $p_{k},(1 \leq k \leq s)$ represents a network in the set $P$ and $p_{k}=\left\{m_{k}, \Theta_{k}\right\}$

4. $m_{k}$ represents the number of ports corresponding to each network $p_{k}$

5. Set $\Theta_{k}$ contains the position $(x, y)$ of every port $m_{k}$ in a network $p_{k}$

6. Also the set $T=t_{1}, t_{2} \ldots t_{s}$ contains a binary digit corresponding to each network in the set $P$. If $t_{k}=1$, it means the following. The corresponding network has to be connected to the bulkhead.

7. n, number of valves in a given circuit

\section{The objective function for the valve stand placement problem}

Consider each imaginary 2-D cell from the partition of the valve stand that houses a valve (Fig. 3a). Physically, on the valve-stand, a valve requires a large area compared to its actual size. The extra accessibility space is required for plumbing, fastening the connectors and maintenance. The valves are also centered in the cells and they are arranged adjacent to one another. The following sets of rules describe the best practices for plumbing with pipes.

\subsection{Plumbing components}

1. A network with a single port in the valve stand needs to be connected from the valve to the bulkhead. This is generally achieved with a single pipe. Refer to network A in Figure $3 b$ for an example.

2. A network with two ports is interconnected with a single piece of pipe bent to interconnect the two ports as shown in Figure 4a.

3. A network with three ports requires a Tee joint. The Tee connector has three legs. The interconnections require three additional pieces of piping to connect between each leg of the Tee connector and the ports (refer Figure $4 \mathrm{~b}$ ).

4. A network interconnecting four ports in an optimal placement is economical with a Cross connector. The Cross connector is shown in Figure 4c. However, the geometrical orientation of the ports can force the use of two Tee connectors-a costlier solution in terms of energy and also material costs.

5. A network with more than four ports requires a combination of Tee and Cross connectors. Judgment, for the routing, based on the above four principles of routing need to be applied. 


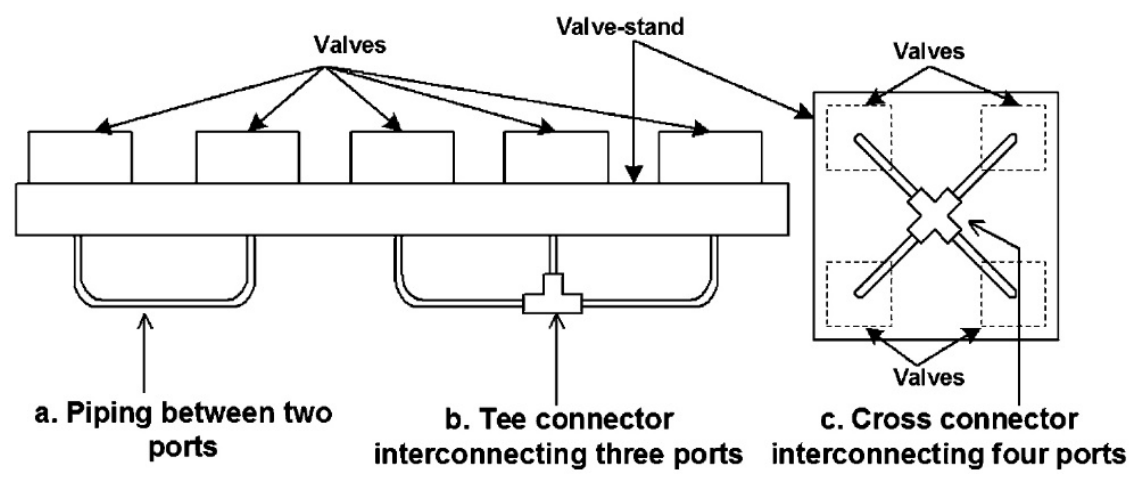

Figure 4. Illustration for the use of plumbing connectors

\subsection{Pressure drop reduction}

1. The pressure drop from the length of piping is given by the Darcy-Wiesbach equation [2], and this is referred to as the major losses. The total length of piping connecting all the networks has to be minimal.

2. The number of connectors and the total number of legs from all the connectors of a network has to be minimal.

3. The number of bends in a network has to be minimal (Bends contribute to minor losses).

In all the computations that ensue, a plumbing length function that represents the composite pressure drops of major, minor, and connector losses is computed.

\subsection{Assumptions}

The following lists the assumptions before we present the objective function.

1. The size of the ports and the distances separating them in a valve are very small compared to the area the valve occupies in a valve-stand. This physical reality has the advantage that all the ports in a valve can be assumed to be located in the center of the cell where the valve resides. In other words, the coordinates $(x, y)$ of the cell of a valve addresses the coordinates of all the ports contained in it.

2. All networks in a given circuit have comparable flow. Guidelines are provided in Section 7 to take care of networks that do not have significant flow.

\subsection{The objective function}

From discussions in Sections 4.1, 4.2, and 4.3, the objective function can now be written as

$$
\text { Minimize } L=\sum_{k=1}^{s} l\left(p_{k}, t_{k}\right)
$$

The function $l$ is the length function for the composite pressure drops of major, minor, and connector losses for a network $p_{k}$ in the set $P$. The function $l$ is described in Section 6.3. $L$ is the sum of the length function of all networks in the valve-stand. 


\section{The EA template}

The EA is a mature concept, and for a comprehensive treatment on EAs, readers may refer to Michalewicz [10]. Figure 5 describes the particular template for the EAs described in this essay.

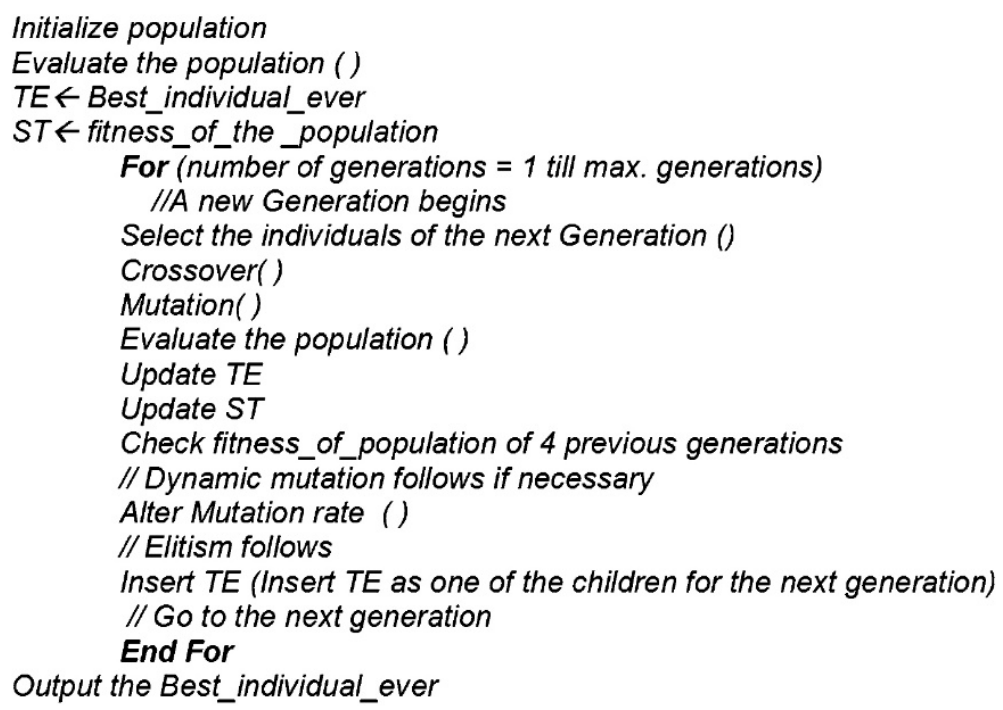

Figure 5. The evolutionary algorithm

The probabilities for selection, crossover, and mutation of the individuals are listed in Table 1. Elitism, the process of breeding the best individual obtained from the previous generations, is applied as follows. The best individual beginning from the initial population (Best_individual_ever) is saved in a separate location. The Best_individual_ever is introduced at a random location in the population in every new generation. After every new generation is evaluated, if a better individual than the stored Best_individual_ever is found, then the Best_individual_ever is updated.

\begin{tabular}{ll}
\hline Table 1. Parameters of EA for VSP & \\
\hline Number of generations & Check Table 6 \\
Selection of individuals for subsequent generations & Roulette wheel \\
Crossover rate & $25 \%$ \\
Default mutation rate & $3 \%$ \\
Dynamic mutation rate & $3.75 \%$ \\
Population size & 100 \\
\hline
\end{tabular}

The dynamic mutation rate is used to perturb the population from settling on local optima. It was implemented as follows based on empirical corroboration. We keep track of the overall fitness of the population (fitness_of_population) of four subsequent generations. The fitness_of_population data of the latest generation is saved and data from the 
oldest generation is deleted. At the end of each generation, the four fitness_of_population values are compared. If all four are found equal, the mutation rate is doubled; otherwise the initial mutation rate is used.

The number of generations (iterations) is decided from experiments, and it is discussed later on. For the set number of iterations, for certain simple problems, the solutions match the best practices or global optimal solutions. In the case of increased complexity, we expect the solutions to be good enough as EAs tend to escape local optima. All the key elements of the EA in Figure 5, representation, initialization, evaluation function, crossover, and mutation are explained in Section 6.

\section{Components of the EA for the valve stand problem}

\subsection{Representation scheme}

A matrix (genotype) of size $n \cdot \times n$ is used to map all the possible locations of the valves on the valve stand (phenotype). The $(x, y)$ position used to address an element of the genotype also serves as the coordinates for the phenotype. A later illustration provides the coordinate system that was observed.

\subsection{Initialization}

The population was initiated by allocating the set of valves $V$ to every individual (matrix with $n \cdot \times n$ elements) in the population at random locations.

\subsection{Evaluation function}

The evaluation of the phenotype is based on the objective function discussed in Section 4. The following steps discuss the computation of the function 1 for individual networks.

The quantitative value $l$ is determined based on the number of ports, how far apart they are, and the types of connector(s) that can be used to interconnect each network. The function $l$ of a network is defined as

$$
l\left(p_{k}, t_{k}\right)=\operatorname{dist}\left(p_{k}\right)+\operatorname{dist}_{b} \cdot t_{k}
$$

where:

$\left\{\operatorname{dist}\left(p_{k}\right)=\right.$ Euclidian distance $\left(\Theta_{k}\right)$ if $\left.m_{k}=2\right\}$,

$\left\{\operatorname{dist}\left(p_{k}\right)=\right.$ Tee distance $\left(\Theta_{k}\right)$ if $\left.m_{k}=3\right\}$, and

$\left\{\operatorname{dist}\left(p_{k}\right)=\right.$ Convex hull perimeter $\left(\Theta_{k}\right)$ if $\left.m_{k} \geq 4\right\}$.

And when $t_{k}$ is $=1$,

$\left\{\right.$ dist $_{b}=$ Euclidian distance between anchor point [11] of the set $\Theta_{k}$ and the bulkhead point $\}$.

1. If $m_{k}=1$, then $l$ represents the Euclidian distance between the location of the port and the location of the bulkhead (here, $\left.\operatorname{dist}\left(p_{k}\right)=0\right)$. The point $(n+1,1)$ was used as the coordinate for bulkhead in our experiments.

2. If $m_{k}=2$, the Euclidian distance " $\mathrm{D}$ " between the port locations, as shown in Figure 6 is calculated. The partial drawing shows a connection between two ports with a bent pipe. 
The two perpendicular lengths $\mathrm{E}$ are not considered in the evaluation since they are omnipresent for any placement or routing solution. Similarly, these perpendicular lengths occur in all the networks, and they are not evaluated.

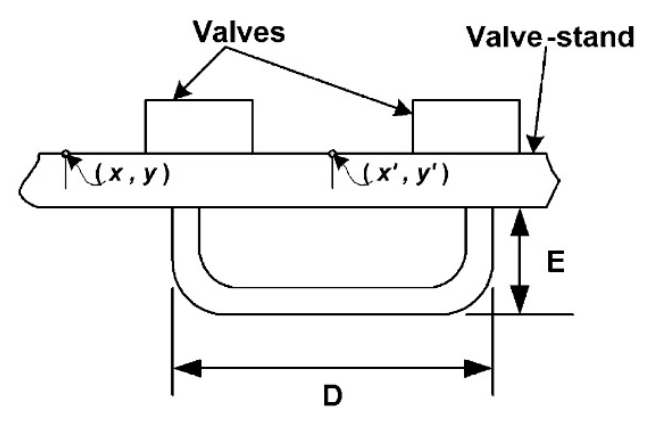

Figure 6. Length of piping between two ports

3. If $m_{k}=3$, three cases of using a Tee joint arise. The location of the ports may occur in a straight line (Fig. 7a), vertices of an isosceles triangle with the unequal side less than the equal sides (Fig. 7b), or vertices of any arbitrary triangle (Fig. 7c) formations. If it is determined that the formation is not the above-mentioned isosceles type, the sum of the distance between the farthest points $(R, S)$ and the perpendicular distance between the straight line joining the two points $(R, S)$ and the third vertex $Q$ is calculated. In the case of isosceles triangle with the shorter unequal side $(\mathrm{SQ}<\mathrm{SR}, \mathrm{QR})$, the sum of shorter distance and the perpendicular distance to the third vertex gives the value of $l$. If the three points are in adjacent cells and in a straight line, then that configuration scores the highest since they have the least number of bends (the Tee connector is aligned perpendicular to the valve-stand as in Fig. 7a) and the length of piping. Note that if the ports are not in a straight line, the Tee joint has to be aligned parallel to the valve-stand for efficient routing.

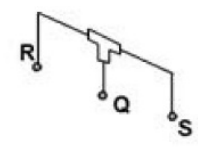

a. Ports $R, S$ and $Q$ in straight line formation

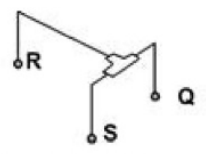

b. Ports $R, S$ and $Q$ in iscoceles triangle formation

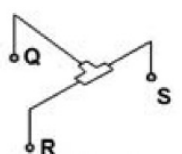

c. Ports R,S and Q in an arbitrary triangle formation

Figure 7. Possible orientations of Tee connector for three port networks

4. If $m_{k} \geq 4$, the perimeter of the convex hull joining the ports is calculated. Graham Scan as described in [11] was used in the implementation with the following modification. If collinear ports are present, the collinear port that is farthest to the anchor point [11] is retained and the rest of the collinear ports are eliminated. The perimeter of the convex hull is used to estimate the spread or the scatter of the ports. It is used for the following reasons. 
a. The size of the convex hull is directly proportional to the length of the plumbing.

b. The perimeter of the convex hull also indicates a longer length requirement if the ports are in a straight line. Straight-line configuration is not optimal, as the plumbing lengths with two Tees would require 3.0 units as opposed to 2.83 units with a cross-connector.

5. If $m_{k}>4$, convex hull perimeter serves as the basis for grading between best and worst cases.

\subsection{Crossover}

For every pair of individuals that undergo crossover, a set of valves $\phi$ is selected $(\varphi \subseteq V)$, based on the crossover rate. Crossover is illustrated in Figure 8. The numbers identify the valves and valves \#2,3,4, and 5 are initially selected for crossover (Fig. 8a). Later, valve \#3 is dropped from crossover. This is because the corresponding position of valve $\# 3$ in parent A is occupied by valve \#1 in parent $B$, and valve \#1 does not participate in the crossover. However, in the case of valve $\# 2$ and valve $\# 5$, they are crossed over because both the valves are selected for crossover.

(a)

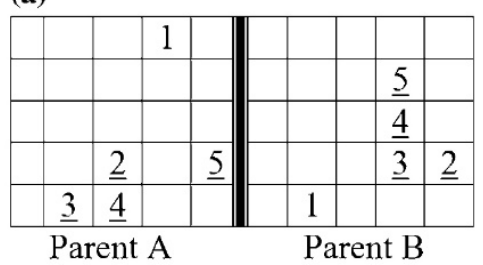

(b)

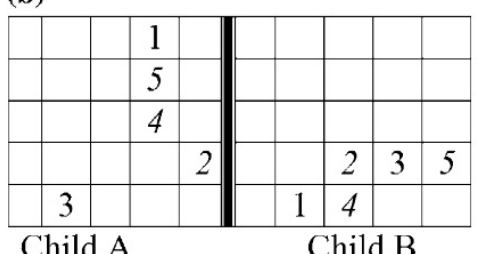

Figure 8. The crossover operator (a) before crossover, (b) after crossover

\subsection{Mutation}

An individual is selected for mutation based on the default or the dynamic mutation rate. Subsequently, for each individual selected for mutation, a new set of valves is selected for mutation on the rate that is equal to 2.25 times the default or the dynamic mutation rate. Next each selected valve in a position $(x, y)$ is swapped with the valve or empty space present in $\left(x^{\prime}, y^{\prime}\right)$; where $\left(x^{\prime}, y^{\prime}\right)$ is a random location in the same individual. This process is shown in Figure 9.

(a)

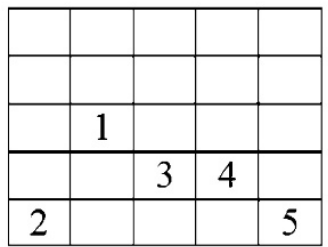

(b)

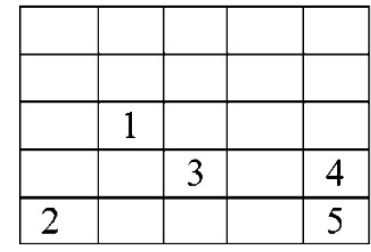

Figure 9. (a) Before mutation. (b) After mutation. Here, valve \#4 is selected and swapped with the valve or the empty space in the other location selected randomly. 


\subsection{Algorithm parameters}

Table 1 lists all the algorithm parameters and probabilities for the different operators. An example of the percentage number is a crossover rate of $25 \%$, which means the following: for the population consisting of 100 individuals, 100 random numbers between 0 and 1 are generated. If the individual's random number is less than 0.25 , then that individual is selected for crossover.

\section{Algorithm output}

Figure 10 shows the final output (Best_individual_ever) from a test run for the example circuit of Figure 1. Removing all unused rows and columns yields Figure 11.

\begin{tabular}{|l|l|l|l|}
\hline $\begin{array}{l}\text { Position } \\
(x=1, y=n)\end{array}$ & & & $\begin{array}{l}\text { Position } \\
(x=n, y=n)\end{array}$ \\
\hline & & & Valve \#1 \\
\hline $\begin{array}{l}\text { Position } \\
(x=1, y=1)\end{array}$ & Valve \#4 & Valve \#3 & $\begin{array}{l}\text { Valve \#2 } \\
\text { Position } \\
(x=n, y=1)\end{array}$ \\
\hline
\end{tabular}

Figure 10. Output of the EA for the example circuit in Figure 1

\begin{tabular}{|c|c|c|}
\hline & & $\begin{array}{c}1 . \text { Relief } \\
\text { valve }\end{array}$ \\
\hline $\begin{array}{l}\text { 4. CB } \\
\text { Valve }\end{array}$ & $\begin{array}{c}\text { 3. Check } \\
\text { Valve }\end{array}$ & $\begin{array}{l}2 . \mathrm{DC} \\
\text { valve }\end{array}$ \\
\hline
\end{tabular}

Figure 11. Solution for Figure 1

The valves can be mounted on the valve-stand as per the configurations shown in Figure 11. Based on the space and orientation requirement of the valves, the actual dimensions of the valve stand can be chosen.

Benchmarks for these installations are not available in literature as the information is proprietary to companies. We consider the arrangement in Figure 3c, d extended from Figure 11 to reflect common best practices as applied by skilled designers and fabricators.

Initially, we made an assumption that all the networks have equal flow rates. This may not be true always. For example, in the circuit shown in Figure 15 (Appendix), the flow through the pressure switch (valve \#5) and the Sol. Operated valve (valve \#3) may only be a few drops or a small volume of the fluid. Such valves should be eliminated before the optimization. Later, in the final solution, they can be added to convenient locations. 


\section{Results and discussion}

\subsection{Example circuits and results}

We first tested the EA with simple circuits before moving to circuits with increased valve complexities. For example, we used a circuit with a single network consisting of four ports and it provided the valve placement solution as per Figure 4c. Further, for circuits with three and four valves, alternative options considered good were computed manually. Good solutions were those that had the cluster of valves closer to the bulkhead. We found that the algorithm's result and best result from manual computations were the same and all the valves clustered closer to the bulkhead. We consider our results to reflect common best-practice design expertise as applied by skilled designers. From the EA, for all the simpler circuits, the global optimal solution was obtained each time. However, with increasing complexity, some trials yielded near-global optimal solutions. The circuits and the best solutions for three example cases from the EA are illustrated in Figures 13, 15, and 17 and Figures 14, 16, and 18 (Appendix), respectively.

\subsection{Algorithm performance}

The EA was written in Java Programming language and the experiments were carried out on a $500 \mathrm{MHz}$ processor with $192 \mathrm{MB}$ RAM. Each example test circuit-Figures 13, 15, and 17-after fine-tuning the algorithm parameters, was run 30 times. For the circuit in Figure 15, all networks were assumed to have equal flow. Depending upon the complexity, the bar on the number of generations to be computed was raised. The results are all tabulated in Table 2.

The frequency of the solutions, from the experiments for three different circuit complexities, toward global optimum is presented in Figure 12. The EA for the circuit with the least complexity, the four-valve circuit from Figure 1, always provided the global optimum. However, with increasing complexities, the occurrence of the globally optimum or the best solution from the 30 runs diminishes. If we set the limits for excellent solutions in the range of $95-100 \%$ of the global optimum, the EA provides it $90 \%$ of the time even for the 12 -valve circuit. 


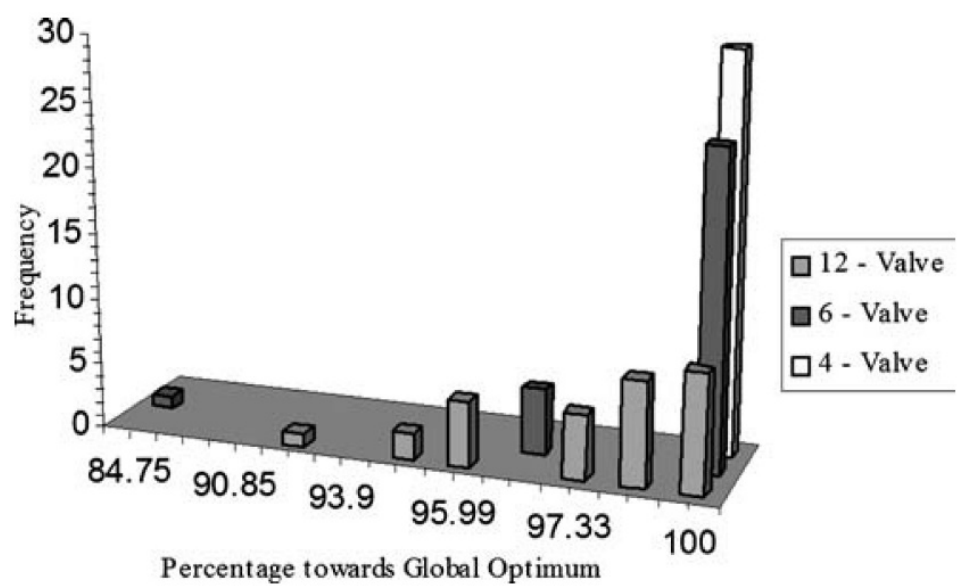

Figure 12. Histogram of frequency of the EA toward achieving global optima for three different circuit complexities

To determine the bar on the number of generations for other valve placement design problems, the data from the latest occurrence (Table 2) can be used to interpolate or extrapolate based on the circuit complexities. The times for computation also indicate that these design solutions can be achieved in reasonable time frames and will considerably aid the output of the designer.

Table 2. Results from experiments for circuits with increasing valve complexities

\begin{tabular}{|c|c|c|c|c|}
\hline \multirow[b]{2}{*}{ S.no } & \multirow[b]{2}{*}{ Observation $\downarrow$} & \multicolumn{3}{|c|}{ Valve complexity $\rightarrow$} \\
\hline & & $\begin{array}{l}4 \text { valves, } \\
5 \text { networks }\end{array}$ & $\begin{array}{l}6 \text { valves, } \\
5 \text { networks }\end{array}$ & $\begin{array}{l}12 \text { valves, } \\
11 \text { networks }\end{array}$ \\
\hline 1 & Number of test runs & 30 & 30 & 30 \\
\hline 2 & Preset number of generations for each test run & 1,000 & 3,000 & 20,000 \\
\hline 3 & $\begin{array}{l}\text { Average number of generations required to reach the } \\
\text { global optimum values for the } 30 \text { test runs (rounded } \\
\text { to the nearest integer) }\end{array}$ & 190 & 635 & 7,516 \\
\hline 4 & $\begin{array}{l}\text { Earliest generation for the occurrence of the optimum } \\
\text { value }\end{array}$ & 1 & 155 & 2,932 \\
\hline 5 & $\begin{array}{l}\text { Latest generation for the occurrence of the optimum } \\
\text { value }\end{array}$ & 747 & 2,623 & 19,145 \\
\hline 6 & $\begin{array}{l}\text { Average time required for the computation of one } \\
\text { generation in seconds }\end{array}$ & 0.0041 & 0.006 & 0.0184 \\
\hline 7 & $\begin{array}{l}\text { Time required for results as per observation five in } \\
\text { seconds }\end{array}$ & 3 & 16 & 351 \\
\hline
\end{tabular}

\section{Conclusions and potential extensions}

In this paper, we have assimilated the best practices for the placement and routing of the valves on the valve-stand. The best practices were used to develop an EA that provides 
excellent valve placement solutions $90 \%$ of the time even for circuits with significant complexity. The placement solutions are optimized to reduce pressure drop in the circuit, thereby conserving energy during the service life of the system.

Computationally, for the 12-valve circuit shown in Figure 17 (Appendix), an exhaustive search could have resulted in evaluating approximately $5 \cdot \times 10^{25}$ possible solutions, which has drastically reduced to evaluating just $2 \cdot \times 10^{6}$ (number of generations $\times$ population size) using the EA. The following are some of the possible extensions of this work.

1. The convex hull was determined for networks with more than four ports. Suitable algorithm has to be determined and applied to optimally route these networks that would eventually reduce the routing burden on the designer.

2. While fluid power systems (>160 LPM) generally use a valve-stand, a 2-D problem, plumbing in chemical industries is a 3-D problem. It would be interesting to see these EA's for such 3-D applications.

Acknowledgments - We would like to thank the group at the Center for Precision Metrology, UNC Charlotte for providing an excellent opportunity and facilities to conduct this work. We are thankful to Professor Zbigniew Michalewicz and Babu Rao for their valuable comments and suggestions.

\section{Appendix}

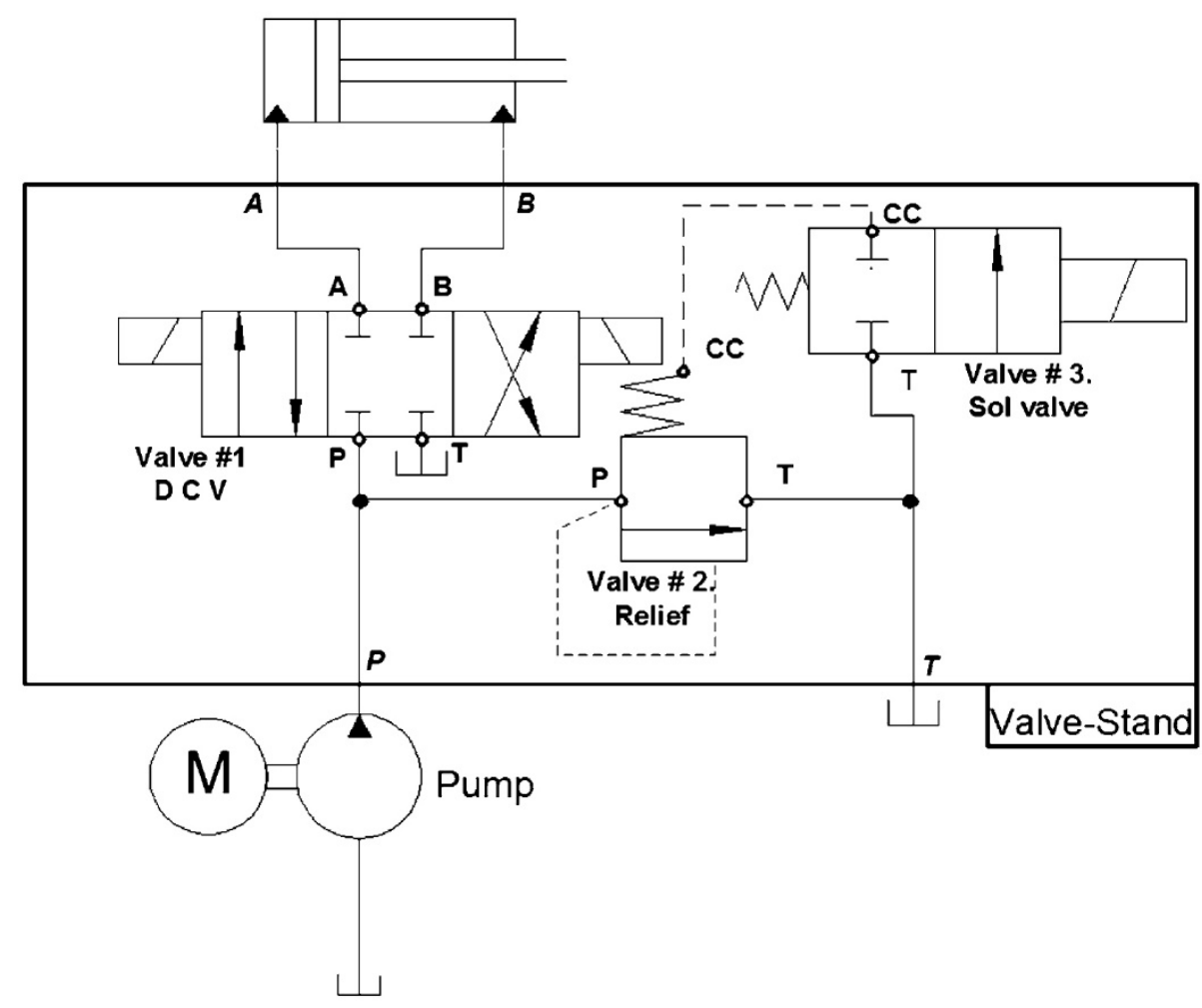

Figure 13. A circuit with three valves 


\begin{tabular}{|c|c|c|}
\hline Valve \#3 & Valve \#2 & Valve \#1 \\
Sol. valve & Relief valve & D C valve \\
\hline
\end{tabular}

Figure 14. Solution from the EA to the circuit with three valves. All unused rows and columns are eliminated. The initial matrix size was $3 \times 3$.

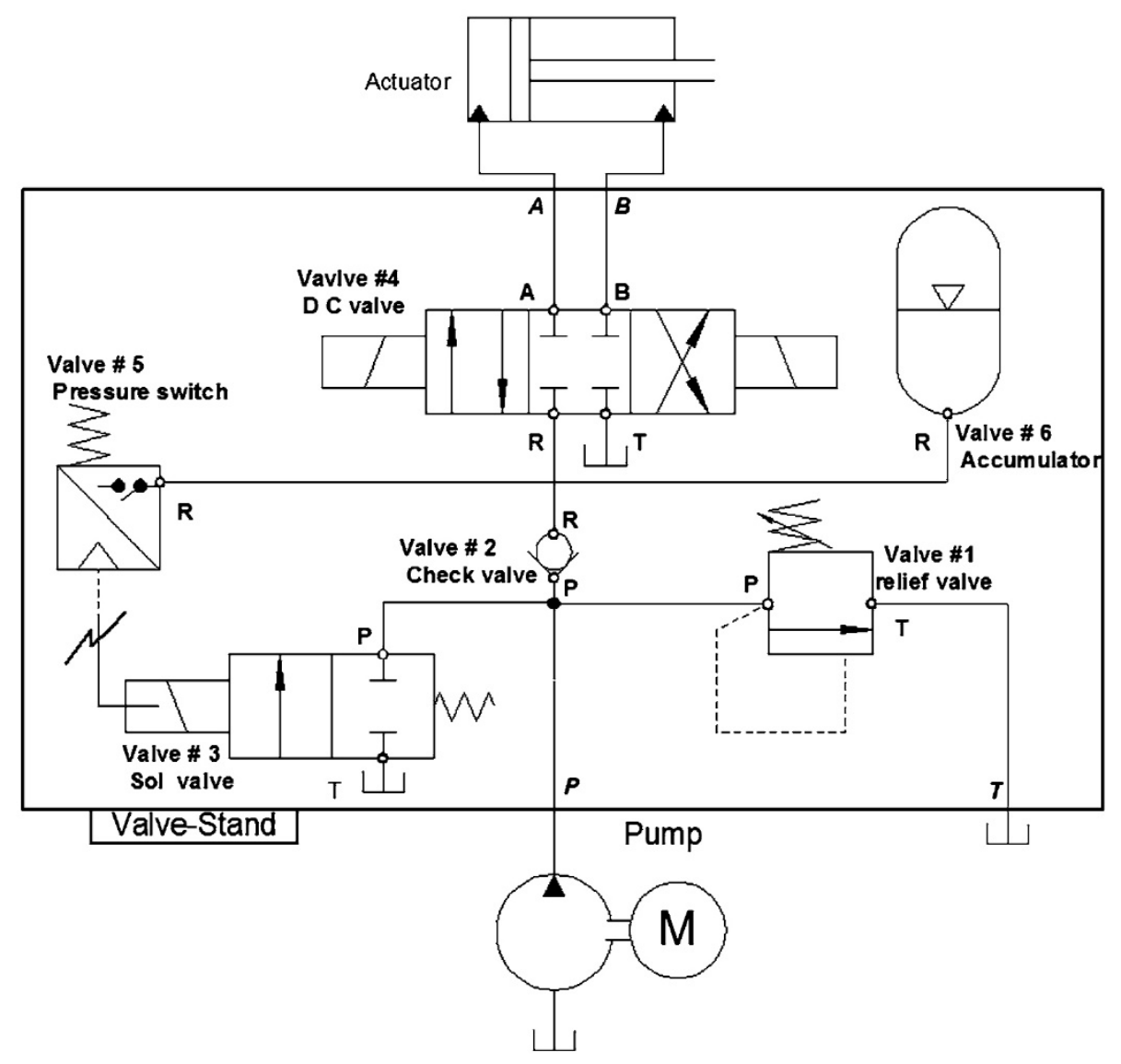

Figure 15. A circuit with six valves 


\begin{tabular}{|c|c|}
\hline Valve \# 5 & Valve \# 6 \\
Pr. switch & Accumulator \\
\hline $\begin{array}{c}\text { Valve \#2. } \\
\text { Check } \\
\text { valve }\end{array}$ & Valve \#4 \\
Dalve \#3. & Valve \\
Sol. valve & Relief valve \\
\hline
\end{tabular}

Figure 16. Solution from the EA to the circuit with six valves. All unused rows and columns are eliminated. The initial matrix size was $3 \cdot \times 3$.

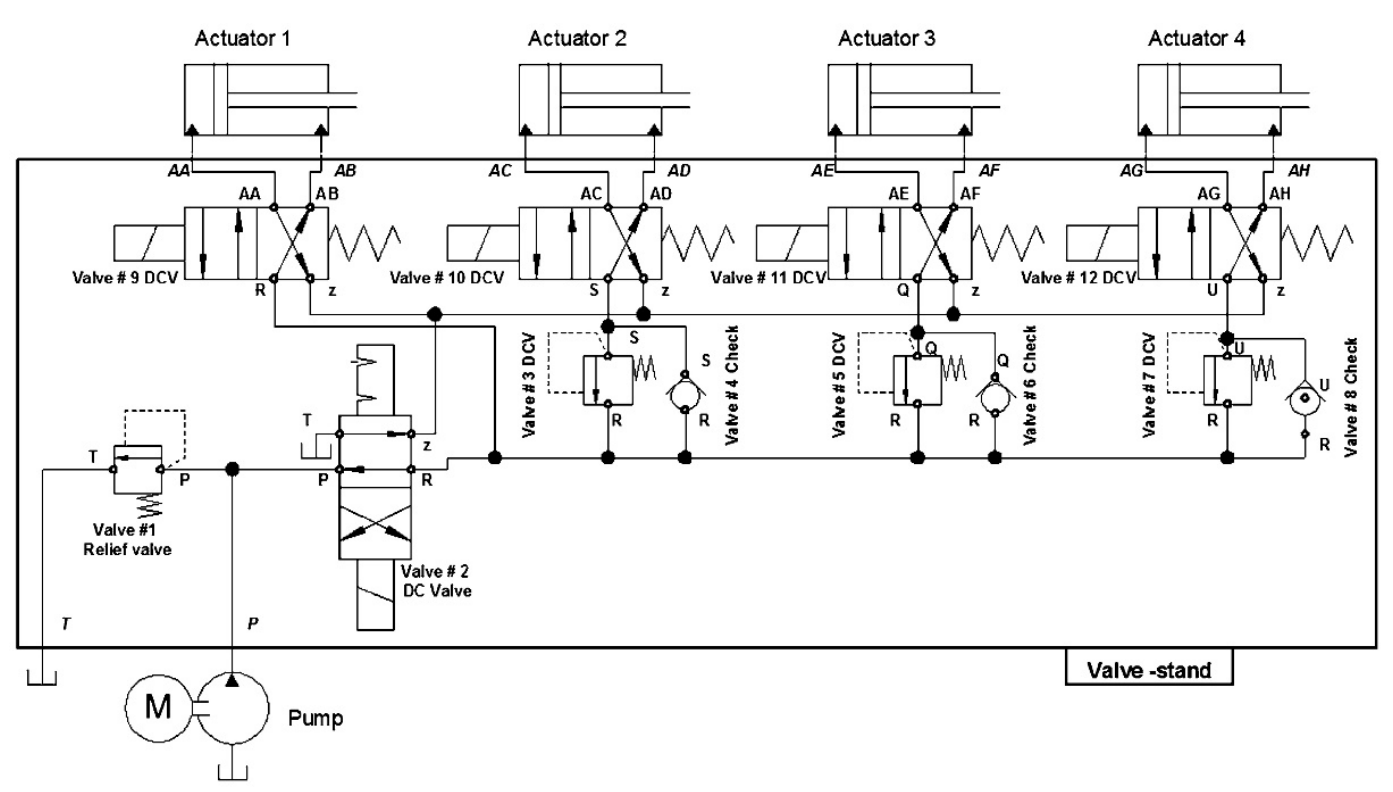

Figure 17. A circuit with 12 valves 


\begin{tabular}{|c|c|c|}
\hline $\begin{array}{c}\text { Valve \#8 } \\
\text { Check valve }\end{array}$ & $\begin{array}{c}\text { Valve \#5 } \\
\text { DCV }\end{array}$ & $\begin{array}{c}\text { Valve \#3 } \\
\text { DCV }\end{array}$ \\
\hline $\begin{array}{c}\text { Valve \#7 } \\
\text { DCV }\end{array}$ & $\begin{array}{c}\text { Valve \# 6 } \\
\text { Check valve }\end{array}$ & $\begin{array}{c}\text { Valve \#4 } \\
\text { Check valve }\end{array}$ \\
\hline $\begin{array}{c}\text { Valve \#12 } \\
\text { DCV }\end{array}$ & $\begin{array}{c}\text { Valve \#11 } \\
\text { DCV }\end{array}$ & $\begin{array}{c}\text { Valve \#10 } \\
\text { DCV }\end{array}$ \\
$\begin{array}{c}\text { Valve \#1 } \\
\text { Relief valve }\end{array}$ & $\begin{array}{c}\text { Valve \#2 } \\
\text { DC Valve }\end{array}$ & $\begin{array}{c}\text { Valve \#9 } \\
\text { DCV }\end{array}$ \\
\hline
\end{tabular}

Figure 18. Solution from the EA to the circuit with 12 valves. All unused rows and columns are eliminated. The initial matrix size was $12 \cdot \times 12$.

\section{References}

[1] Burkard RE, Karisch SE, Rendl F (1997) QAPLIB - a quadratic assignment problem library. J Global Opt 10:391-403

[2] Henke RW (1983) Fluidpower systems and circuits. Penton Education Division, Cleveland

[3] BFPA/P5 (1999) Guidelines to the selection and application of tube couplings for use in fluidpower systems. BFPA publications, Oxfordshire

[4] Smith WW (1989) Computer software for the plumbing engineer. Heat Piping Air Cond 61:105-110

[5] Schechner Y (1990) CAD shines in hydraulic manifold design. Hydraul Pneumat 43(3):16-25

[6] Lienig J, Thulasiraman K (1994) A genetic algorithm for channel routing in VLSI circuits. Evol Comput 1:293-311

[7] Lee C (1961) An algorithm for path connections and its applications. IRE Trans Electron Comput September:346-365

[8] Wang R et al (2000) CAD of hydraulic manifold with object-oriented feature-based solid modeling. Proc Int Fluid Power Exp Tech Conf 100(7.5)187-191

[9] Simon HA (1955) A behavioral model of rational choice. Q J Econ 69:99-118

[10] Michalewicz Z (1994) Genetic algorithms + data structures = evolutionary programming. Springer, Berlin Heidelberg New York

[11] Joseph O (1998) Computational geometry in C. Cambridge University Press, New York 